\title{
The American Society of Peri-Anaesthesia Nurses Annual Conference, Washington DC, USA
}

\author{
Jessica Inch \\ BJARN Editor
}

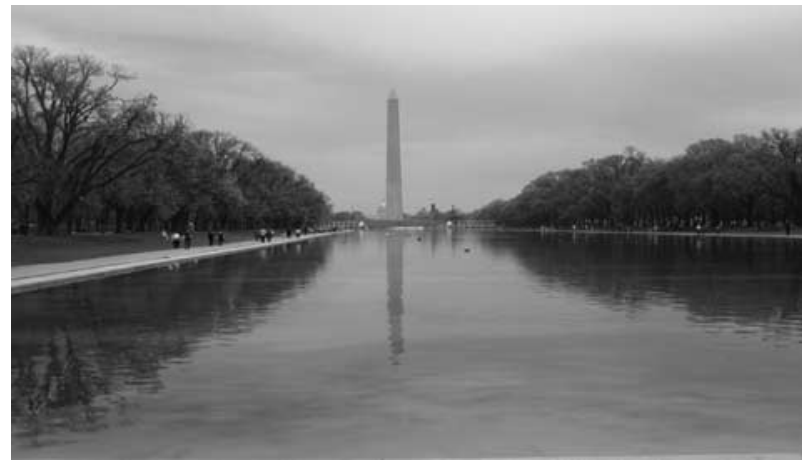

$\mathrm{T}$ he times they are a-changing. At least it feels like they are. When I visited the US this year, it was so with intrigue. We had all watched the Presidential inauguration of Barack Obama back in January and felt the new hope and readiness for change that had flooded not only the US, but seemingly the entire world. Despite being under the cloud of 'economic disaster', America feels optimistic and ready for transparency, which was apparent during this conference entitled 'Dreams Create Lasting Legacies'. President Obama was publicly supported by some of the largest American nursing associations and it is not hard to see why. He stands for social change that ultimately seeks to protect society's weakest individuals, a theme at the heart of all nursing specialities. As you will have read in my Editorial, Jay Rifenbary combined these core values in an excellent opening speech about real democracy, responsibility and the defining of one's personal and professional values. Below is an account of two of the sessions I attended.

\section{New Nursing Graduates in the PACU: Building a Successful PACU Nurse}

\author{
Lynnae Elliotte, RN, MSN, CCRN and Sheryl Cosme, RN, MSN
}

$\mathrm{T}$ he use of new graduate nurses in the PACU is a new phenomenon but a necessary one because of today's nursing shortage. This session presented the planning, implementation and evaluation methods used for the Georgetown University Hospital's Perianaesthesia Internship Programme.

This session dealt with how Georgetown University Hospital has approached the training needs of the newly qualified nurses recruited into the PACU and critical care environment. Due to the nursing shortage, more and more newly qualified nurses are filling posts in the PACU and Recovery, which traditionally had been filled by experienced recovery nurses. It can be expensive to get these new nurses up and running. This hospital prides itself on a programme that not only orientates the individual to the hospital, but also uses extra special touches like scheduled meetings with managers and educators on a regular basis. This is a 6-month course that mixes scheduled clinical classes with ward-based learning. 


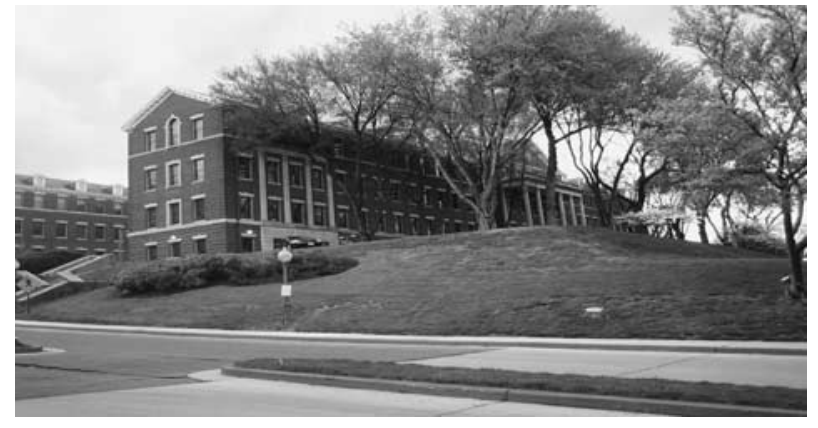

Ward-based time is increased during this set time and culminates with competencies based on the ASPAN guidelines as well as the completion of the Critical Care course.
What makes this course stand out, for me, is the continued emphasis on professional and personal growth, with the newly qualified nurse being encouraged to get involved in political activity. The idea being that the nurse that then enters the work place is a well-rounded individual that is an advocate for the profession as well as the patient. This implementation for new nurses has resulted in a waiting list for new graduates to join the hospital as well as an increased number going on to complete Masters Programmes. Most course attendees go on to become preceptors for new recruits and units have reported higher levels of teamwork and support. Although this is a large programme for a large hospital, aspects can be successfully applied to all units and hospitals irrespective of size.

\title{
Herbal Agents and the Peri-anaesthesia Patient: What's Good, What's Bad, and What's Scary!
}

\author{
Linda Ziolkowski, MSN, RN, CPAN
}

$\mathrm{T}$ This lecture looked at the increased consumer interest for complementary medicines and what this means for the patient having surgery. With the introduction of the Internet market and an increased interest in fitness and health education, more people are turning to complementary medicines. Dissatisfaction with traditional medicine has also led to media promotion of such therapies and self-treatments. However, the public is often misinformed of the benefits and potential interactions of these 'drugs', which is worrying due to the fact that more and more individuals suffer from co-morbidities. Often the advice we receive about these drugs are from magazines and inexperienced individuals working in health food stores.

In the States, research found that $67 \%$ of surgical patients took some form of herbal medication, with $49 \%$ combining more than one. The most likely of these individuals to do so were healthy, college- educated females under the age of 40 . The most regularly used herbal substance was arnica, used for anti-inflammatory effect; it can, however, cause cardio toxicity in larger doses. A total of $34 \%$ of these surgical patients took vitamin E, garlic, ginkgo, ginseng, ginger and fish oils that can all inhibit the coagulation cascade.

The explanation stated above makes pre-operative testing even more vital in terms of history taking. However, it is often difficult to get patients to realise that these are still 'medications' when dealing with surgery. It is vital that time is taken to ask more than once about current medications taken, considering that the individual may be embarrassed about the reasons for taking it. It is important that a clear idea of why they are being used, for how long they have taken them and where they were obtained from is established. 